\title{
A cross-sectional survey of burnout in a sample of resident physicians in Sudan
}

Yasir Ahmed Mohamed Elhadi ${ }^{\mathbf{1 , 2}}$, Abdelmuniem Ahmed ${ }^{\mathbf{3}}$, Elhadi B. Salih ${ }^{\mathbf{4}}$, Osman S. Abdelhamid $^{\mathbf{5}}$, Mohamed Hayder Hamid Ahmed ${ }^{\mathbf{6}}$, Noha Ahmed El Dabbah ${ }^{1}$

1. Department of Health Administration and Behavioral Sciences, High Institute of Public Health Alexandria University, Alexandria, Egypt

2. Department of Public Health, Medical Research Office, Sudanese Medical Research Association, Khartoum, Sudan

3. Physiology Department, Faculty of Medicine, University of Gezira, Sudan

4. Medical officer, Federal Ministry of Health, Khartoum, Sudan

5. Teaching Assistant, Faculty of Medicine, Ahfad University for Women, Sudan

6. Resident Physician, Sudanese Medical Specialization Board, Wad-Medani, Sudan

*Corresponding author: Yasir Ahmed Mohammed Elhadi

Department of Health Administration and Behavioral Sciences, High Institute of Public Health, Alexandria University, Egypt

Address: 165 El Horreya Avenue, 21561 Alexandria, Egypt

E-mail; hiph.yelhadi@alexu.edu.eg 


\begin{abstract}
Background Resident physicians in Sudan suffer multiple physical and psychological stressors. Nevertheless, the prevalence of burnout among this critical population remains unknown. The purpose of this study was to estimate the prevalence of burnout and its related factors in a sample of Sudanese resident physicians.
\end{abstract}

Methods: A cross-sectional design was used to assess burnout among resident physicians at the teaching hospitals of Wad-Medani, Gezira state in Sudan. All resident physicians across nine hospitals were asked to join the study. The Arabic version of Maslach Burnout Inventory was distributed to respondents from July to October 2021.

Results: Out of 300 resident physicians $69.3 \%$ responded. The study population had a mean age of $29.99 \pm 3.01$ years, more than half were females $(56.7 \%)$ and single (59.6\%). In total, $86.1 \%$ met the criteria for burnout in at least one dimension, and $13.9 \%$ in all three dimensions.70.7\% suffer from a high level of burnout on the dimension of emotional exhaustion (EE), while $44.2 \%$ reported a high level on depersonalization (DP) and $73.1 \%$ experienced a sense of decreased professional accomplishment (PA). There were significant differences in the levels of burnout, EE and DP among different specialties. Burnout syndrome was associated with working hours per single duty; with participants working for more than 24 hours had experienced higher levels of burnout, EE and DP.

Conclusions: High prevalence of burnout syndrome was found in this sample of resident physicians in Sudan. Stakeholders should urgently implement effective remedies to protect the mental health of resident physicians.

Keywords: Maslach, burnout, resident physicians, Sudan 


\section{Background}

Burnout syndrome (BOS) was first described by Freudenberg in 1974 [1]. In the $11^{\text {th }}$ revision of the International Classification of Diseases, BOS has been classified as an occupational phenomenon. It was defined as "A syndrome regarded stemming from continuous work stress that has not been properly managed"[2]. Burnout is characterized by three sub-dimensions; high emotional exhaustion, an increase in the mental distance from the profession; high depersonalization, a skepticism about the career; and a sense of decreased professional achievement [3].

Evidence suggests that healthcare workers suffer from high levels of BOS [4-6] with trainee physicians being at increased risk of BOS compared to other healthcare workers [7, 8]. Among trainee physicians, several occupational and individual factors have been recognized. However, it is uncertain which factors are the most significant in promoting the development of BOS [9].Work-related factors vary among different medical departments, which might suggest that there are certain fundamental disparities in working environments that can be linked to BOS among these populations [9]. BOS also appears to be influenced by payment models, with physicians who only receive incentive or performance-based pay have considerably higher burnout rates than salary paid physicians. [10, 11] BOS is influenced by the organizational context such as negative leadership behaviors and inadequate interprofessional collaboration, as well as possibilities for growth and social support for physicians [12]. BOS is also linked to poor work conditions, increased work demands, work-life imbalance, postgraduate training requirements interfering with personal life, and lack of senior support[9]. physicians' burnout is not only financially costly, but also has a slew of other consequences, leaving Medicine is a clear example of such consequences [13]. In addition, depression, marital complications, medical errors, substance abuse, and suicidal behavior might occur [14]. Such consequences have detrimental impacts on healthcare organizations, physicians, and the quality of patient care provided [13] .

The Sudan Medical Specialization Board (SMSB) is the professional training organization responsible for managing and delivering medical and health specialized programs in Sudan [15]. Sudan has been struggling to coordinate between human resources for health policies and the overall health planning. Because of the lack of coordination between the health authorities -represented by the Federal Ministry of Health- and medical training sector - represented in SMSB - there has been an imbalance between the training and production of health professionals in certain professions [16]. In addition, the mass migration of qualified health workers due to the economic crisis has left Sudan with a severe shortage in terms of qualified trainers. Moreover, the 
privatization of the health sector during the previous regime in Sudan has made the remaining qualified practitioners much less available for the education and training in teaching hospitals, which in turn affected the quality of medical training [17].

Despite being founded in 1995, the SMSB has just started paying less than 100 \$ per month salary to resident physicians in 2021. At the same time, doctors accepted by training programs have to pay annual training fees to the SMSB, posing extreme financial burden on resident physicians and forces them to work extra-hours in private hospitals or clinics to cover their daily living expenses. This in turn affects their training quality and the time they have for academic achievement, which pose further risk for stress and burnout [18]. The training period ranges from four to seven years depending on the chosen specialty. For a considerable portion of the training period, a resident physician would have to work in other state hospitals in Sudan, away from their homes and families due to the SMSB random distribution of trainees. This scenario suggests extreme psychological and mental health impacts among resident physicians in Sudan that warrants urgent investigation to propose effective remedies. The purpose of this study was to estimate the prevalence rate of burnout and its associated factors in a sample of Sudanese resident physicians.

\section{Material and Methods}

\section{Study design and setting}

A cross-sectional design was used for this study. This survey was conducted at the teaching hospitals of Wad-Medani district, Gezira state, Southeast Sudan. There are nine teaching hospitals in Wad-Medani covering nine medical specialties, serving more than 3 million Sudanese population and affiliated with the University of Gezira-Faculty of Medicine, were selected for this study. The 300 resident physicians at dermatology, general surgery, pediatrics, obstetrics and gynecology, psychiatry, ear nose and throat, oncology, urology, and internal medicine departments, were approached and invited to participate in the present study.

\section{Data collection procedures}

Data were collected from July to October 2021 through self-administered questionnaire that was comprised of two sections. The first section included the informed consent and other items related to sociodemographic and work-related attributes of participants including age, sex, marital status, specialty, and working hours/duty.

The second section contained the Arabic validated version of the Maslach Burnout Inventory Human Services Survey (MBI-HSS) [19], used after obtaining the required permissions from Mind Garden, Inc., an independent publisher of tools and instruments for psychological assessments of burnout, anxiety and leadership among others [20]. The 
MBI-HSS is the most accepted and widely used instrument for measuring burnout syndrome [21]. It consists of 22 items that investigate the three dimensions of BOS; nine questions for emotional exhaustion (EE); five questions for depersonalization (DP); and eight question for personal achievement (PA). Each item was ranked on a seven-point frequency rating scale, ranging from never (score 0) to every day (score 6). Higher scores on the EE and DP subscales were associated with higher levels of burnout, whereas high level of PA was associated with lower levels of burnout.

\section{Search strategy}

In a similar fashion to other cross-sectional studies of burnout among healthcare workers [22], we performed online data search to compare burnout rates between resident physicians in Sudan and other countries. We searched PubMed database for similar crossspecialty studies of burnout among resident physicians published between 2000-2021. We excluded studies reporting burnout rate among single specialty resident physicians. The search results were evaluated by the authors and relevant studies were included and extracted on an excel sheet. The reported burnout rates in each included study were compared against the results of the current study.

\section{Data management and statistical analysis}

Data were analyzed using IBM SPSS software package version 20.0. The KolmogorovSmirnov test was employed to ensure the normal distribution of variables. The three subscales for measuring burnout were categorized according to the scoring system of MBI-HSS [3] The Cronbach Alpha for the MBI-HSS in this study was 0.79 indicating the high reliability of the overall measurement. For normally distributed quantitative variables, the student t-test was used to compare two groups, while ANOVA was used to compare more than two groups. Significance of the results obtained was judged at the 5\% level of alpha error.

\section{Ethical considerations}

The current study was performed in accordance with research ethical standards and guidelines. The study was approved by the Health Sector Ethical Review Committee, University of Gezira (IRB approval No: 00036-21). Anonymity and confidentiality of data were guaranteed. A written consent to participate was included in the data collection tool and obtained from all participants. The right to withdraw from the study at any time was clearly stated prior to the start of the study. 


\section{Results}

The sociodemographic and work-related characteristics of respondents are shown in Table 1. A total of 208 resident physicians with mean age of $29.99 \pm 3.01$ years participated in the present study (69.3\% response rate). More than half of respondents were females $(56.7 \%)$, single $(59.6 \%)$ and senior resident physicians $(50.5 \%)$. Most of participants were medicine specialty residents $(29.8 \%)$. More than one third reported working for more than 24 hours per single duty (32.7\%) (Table 1).

Table (1): Sociodemographic and work-related characteristics of respondents

\begin{tabular}{|c|c|c|}
\hline $\begin{array}{c}\begin{array}{c}\text { Socio demographic } \\
\text { characteristics }\end{array} \\
\end{array}$ & No & $\%$ \\
\hline \multicolumn{3}{|l|}{ Age (years) } \\
\hline$<30$ & 104 & 50 \\
\hline $30-<35$ & 84 & 40.4 \\
\hline$\geq 35$ & 20 & 9.6 \\
\hline \multicolumn{3}{|c|}{ Mean \pm Standard Deviation $=29.99 \pm 3.01$} \\
\hline \multicolumn{3}{|c|}{ Gender } \\
\hline Male & 90 & 43.3 \\
\hline Female & 118 & 56.7 \\
\hline \multicolumn{3}{|l|}{ Marital status } \\
\hline Single & 124 & 59.6 \\
\hline Married & 81 & 38.9 \\
\hline Divorced/Widowed & 3 & 1.4 \\
\hline \multicolumn{3}{|l|}{ Specialty } \\
\hline Medicine & 62 & 29.8 \\
\hline Pediatrics & 38 & 18.3 \\
\hline Urology & 13 & 6.3 \\
\hline Obstetrics \& Gynecology & 26 & 12.5 \\
\hline Surgery & 38 & 18.3 \\
\hline ENT & 7 & 3.4 \\
\hline Oncology & 9 & 4.3 \\
\hline Dermatology & 13 & 6.3 \\
\hline Psychiatry & 2 & 1 \\
\hline \multicolumn{3}{|l|}{ Years of residency experience } \\
\hline$<3$ & 103 & 49.5 \\
\hline$\geq 3$ & 105 & 50.5 \\
\hline \multicolumn{3}{|c|}{ Mean \pm Standard Deviation $=2.46 \pm 1.05$} \\
\hline \multicolumn{3}{|c|}{ Working hours per duty } \\
\hline 8 to11 hours & 37 & 17.8 \\
\hline 12 to 17 hours & 50 & 24 \\
\hline 18 to 24 hours & 53 & 25.5 \\
\hline
\end{tabular}


The prevalence of burnout syndrome and its dimensions among resident physicians are shown in Table $2.70 .7 \%$ of resident physicians suffer from a high level of burnout on the dimension of emotional exhaustion, while $44.2 \%$ reported high levels on depersonalization and $73.1 \%$ experienced a sense of decreased professional accomplishment. Overall, $86.1 \%$ met the criteria for burnout in at least one dimension, and $13.9 \%$ in all three dimensions.

Table (2): Frequencies of resident physicians by the levels of burnout in the three dimensions

\begin{tabular}{|l|c|c|c|}
\hline \multicolumn{1}{|c|}{ Burnout and Symptoms } & Low & Moderate & High \\
\hline Emotional exhaustion (EE) $^{\mathrm{a}}$ & $28(13.5 \%)$ & $33(15.9 \%)$ & $147(70.7 \%)$ \\
\hline${\text { Depersonalization }(\mathrm{DP})^{\mathrm{b}}}^{\mathrm{y}}$ & $52(25.0 \%)$ & $64(30.8 \%)$ & $92(44.2 \%)$ \\
\hline${\text { Personal accomplishment }(\mathrm{PA})^{\mathrm{c}}}^{*}$ & $18(8.7 \%)$ & $38(18.3 \%)$ & $152(73.1 \%)$ \\
\hline Overall burnout $^{*}$ & $4(1.9 \%)$ & $175(84.1 \%)$ & $29(13.9 \%)$ \\
\hline
\end{tabular}

${ }^{\mathrm{a}}$ Score $\square$ of $\leq \square 16$ denoted a low level, score 17 to 26 denoted a moderate level, and score $\geq 27$ denoted a high level

${ }^{\mathrm{b}}$ Score $\square$ of $\leq \square 6$ denoted a low level, 7 to 12 denoted a moderate level, and score $\geq 13$ denoted a high level.

${ }^{\mathrm{c}}$ Score $\square$ of $\geq \square 39$ indicated low level, 32 to 38 denoted a moderate level; $\leq 31$ denoted a high level.

Overall burnout $=$ burnout in all three dimensions (low scores on the EE and DP subscales, with a high score on the PA subscale, denoted a low degree of overall burnout; while high scores on the EE and DP subscales, with a low score on the PA subscale, denoted a high degree of burnout.

Parameters associated with burnout are shown in table 3. There were significant differences in the levels of emotional exhaustion (EE), depersonalization (DP) and the overall burnout among different specialties, with the Pediatric resident physicians showed higher overall burnout [mean $\pm \mathrm{SD}, 3.19 \pm 0.86(\mathrm{P}<0.001)$ ], higher $\mathrm{EE}$ [mean $\pm \mathrm{SD}, 4.36$ $\pm 1.26(\mathrm{P}<0.001)]$, and higher DP [mean $\pm \mathrm{SD}, 3.09 \pm 1.32)(\mathrm{P}<0.001)]$. Burnout, EE and DP were significantly associated with the working hours per single duty; with physicians working for more than 24 hours per a single duty, has experienced higher levels of burnout, EE and DP $(\mathrm{P}<0.001)$. However, there was no significant differences exist in the level of professional accomplishment related to respondents' sociodemographic and work-related characteristics. Additionally, there were no significant differences noted in the levels of burnout and its three dimensions among different age groups, gender, years of experience, or marital status of resident physicians (Table 3). 
medRxiv preprint doi: https://doi.org/10.1101/2021.11.25.21266880; this version posted November 28, 2021. The copyright holder for this preprint (which was not certified by peer review) is the author/funder, who has granted medRxiv a license to display the preprint in perpetuity.

It is made available under a CC-BY-NC-ND 4.0 International license .

\begin{abstract}
Table (3): Parameters associated with burnout syndrome and its dimensions among resident physicians in Sudan
\end{abstract}

\begin{tabular}{|c|c|c|c|c|c|}
\hline \multirow[t]{2}{*}{ Socio-demographic characteristics } & \multirow{2}{*}{$\mathbf{N}$} & \multirow{2}{*}{\begin{tabular}{|c|}
$\begin{array}{c}\text { Emotional } \\
\text { exhaustion }\end{array}$ \\
Mean \pm SD. \\
\end{tabular}} & \multirow{2}{*}{$\begin{array}{c}\begin{array}{c}\text { Depersonalizati } \\
\text { on }\end{array} \\
\text { Mean } \pm \text { SD. } \\
\end{array}$} & \multirow{2}{*}{\begin{tabular}{|c|}
$\begin{array}{c}\text { Personal } \\
\text { accomplishment }\end{array}$ \\
Mean \pm SD. \\
\end{tabular}} & \multirow{2}{*}{$\begin{array}{c}\begin{array}{c}\text { Overall } \\
\text { burnout }^{\mathrm{a}}\end{array} \\
\text { Mean } \pm \text { SD. }\end{array}$} \\
\hline & & & & & \\
\hline \multicolumn{6}{|l|}{ Age (years) } \\
\hline$<30$ & 104 & $3.90 \pm 1.36$ & $2.95 \pm 1.31$ & $4.06 \pm 1.05$ & $2.97 \pm 0.83$ \\
\hline $30-<35$ & 84 & $3.80 \pm 1.48$ & $2.88 \pm 1.28$ & $4.28 \pm 1.05$ & $2.84 \pm 0.98$ \\
\hline$\geq 35$ & 20 & $3.32 \pm 1.51$ & $2.47 \pm 1.30$ & $4.29 \pm 1.0$ & $2.54 \pm 1.10$ \\
\hline $\mathbf{F}(\mathbf{p})$ & & $1.401(0.249)$ & $1.150(0.319)$ & $1.184(0.308)$ & $1.965(0.143)$ \\
\hline \multicolumn{6}{|l|}{ Gender } \\
\hline Male & 90 & $3.70 \pm 1.35$ & $3.03 \pm 1.15$ & $4.16 \pm 1.05$ & $2.87 \pm 0.90$ \\
\hline Female & 118 & $3.88 \pm 1.48$ & $2.76 \pm 1.39$ & $4.17 \pm 1.04$ & $2.88 \pm 0.94$ \\
\hline $\mathbf{t}(\mathbf{p})$ & & $0.916(0.361)$ & $1.517(0.131)$ & $0.077(0.939)$ & $0.075(0.940)$ \\
\hline \multicolumn{6}{|l|}{ Specialty } \\
\hline Medicine & 62 & $3.93 \pm 1.23$ & $3.05 \pm 1.22$ & $4.20 \pm 1.07$ & $2.95 \pm 0.87$ \\
\hline Pediatric & 38 & $4.36 \pm 1.26$ & $3.09 \pm 1.32$ & $4.07 \pm 0.97$ & $3.19 \pm 0.86$ \\
\hline Urology & 13 & $3.32 \pm 1.34$ & $2.66 \pm 0.81$ & $3.99 \pm 0.96$ & $2.69 \pm 0.71$ \\
\hline OBS \& Gynae & 26 & $4.27 \pm 1.26$ & $3.45 \pm 1.26$ & $4.48 \pm 0.91$ & $3.08 \pm 0.86$ \\
\hline Surgery & 38 & $3.84 \pm 1.46$ & $2.89 \pm 1.25$ & $4.23 \pm 1.20$ & $2.87 \pm 0.98$ \\
\hline ENT & 7 & $3.54 \pm 0.90$ & $2.46 \pm 1.35$ & $4.27 \pm 0.60$ & $2.64 \pm 0.78$ \\
\hline Oncology & 9 & $3.68 \pm 1.07$ & $2.40 \pm 1.23$ & $3.72 \pm 0.65$ & $2.88 \pm 0.80$ \\
\hline Dermatology & 13 & $1.46 \pm 0.82$ & $1.29 \pm 0.76$ & $4.13 \pm 1.0$ & $1.57 \pm 0.65$ \\
\hline Psychiatry & 2 & $2.44 \pm 3.14$ & $1.0 \pm 1.41$ & $2.94 \pm 3.09$ & $2.34 \pm 0.48$ \\
\hline $\mathbf{F}(\mathbf{p})$ & & $7.494^{*}(<0.001 *)$ & $4.727^{*}\left(<0.001^{*}\right)$ & $0.965(0.464)$ & $4.820^{*}\left(<0.001^{*}\right)$ \\
\hline \multicolumn{6}{|l|}{ Years of residency experience } \\
\hline$<3$ & 103 & $3.73 \pm 1.51$ & $2.83 \pm 1.35$ & $4.09 \pm 1.08$ & $2.86 \pm 0.97$ \\
\hline$\geq 3$ & 105 & $3.87 \pm 1.34$ & $2.92 \pm 1.25$ & $4.24 \pm 1.01$ & $2.89 \pm 0.88$ \\
\hline$t(p)$ & & $0.722(0.471)$ & $0.461(0.645)$ & $1.016(0.311)$ & $0.186(0.853)$ \\
\hline \multicolumn{6}{|l|}{ Marital status } \\
\hline Single & 124 & $3.87 \pm 1.35$ & $3.0 \pm 1.26$ & $4.10 \pm 1.02$ & $2.95 \pm 0.83$ \\
\hline Married & 81 & $3.75 \pm 1.50$ & $2.73 \pm 1.34$ & $4.25 \pm 1.09$ & $2.79 \pm 1.03$ \\
\hline Divorced/Widowed & 3 & $2.63 \pm 2.29$ & $1.73 \pm 0.42$ & $4.79 \pm 0.56$ & $1.91 \pm 1.22$ \\
\hline $\mathbf{F}(\mathbf{p})$ & & $1.199(0.304)$ & $2.262(0.107)$ & $1.027(0.360)$ & $2.455(0.088)$ \\
\hline \multicolumn{6}{|l|}{ Working hours per duty } \\
\hline 8 to11 hours & 37 & $2.72 \pm 1.61$ & $1.98 \pm 1.47$ & $3.80 \pm 1.14$ & $2.36 \pm 1.05$ \\
\hline 12 to 17 hours & 50 & $3.69 \pm 1.13$ & $2.77 \pm 1.03$ & $4.37 \pm 0.84$ & $2.73 \pm 0.74$ \\
\hline 18 to 24 hours & 53 & $4.06 \pm 1.30$ & $3.07 \pm 1.16$ & $4.13 \pm 0.98$ & $3.04 \pm 0.80$ \\
\hline More than 24 hours & 68 & $4.27 \pm 1.30$ & $3.29 \pm 1.25$ & $4.26 \pm 1.13$ & $3.13 \pm 0.94$ \\
\hline $\mathbf{F}(\mathbf{p})$ & & $\begin{array}{l}\text { 11.979* }^{*} \\
\left(<0.001^{*}\right)\end{array}$ & $9.733^{*}\left(<0.001^{*}\right)$ & $2.372(0.072)$ & $7.067^{*}\left(<0.001^{*}\right)$ \\
\hline
\end{tabular}

t: Student t-test

F: $\mathrm{F}$ for ANOVA test

N: Number

$\mathrm{p}$ : $\mathrm{p}$ value for comparing between the different categories 
*: Statistically significant at $\mathrm{p} \leq 0.05$

${ }^{a}$ Overall burnout indicate high scores for burnout in all three dimensions

Comparison of burnout rates among resident physicians in Sudan and other countries

The database search has generated 720 potentially relevant articles. After title, abstract and full texts screening, only 11 studies were included. The size of studies ranged from 68 in USA to 3350 in Syria. All included studies have reported higher prevalence of burnout syndrome compared to the current study. However, resident physicians in Sudan experienced higher levels of emotional exhaustion and depersonalization compared to resident physicians in the USA, KSA, Taiwan, Nigeria and Canada (Table 4).

Table (4): Comparing the present study results with other studies evaluating burnout among residents

\begin{tabular}{|c|c|c|c|c|}
\hline $\begin{array}{l}\text { Author, } \\
\text { Year }\end{array}$ & Country & $\begin{array}{l}\text { Sample } \\
\text { size }\end{array}$ & Burnout rates & $\begin{array}{l}\text { Comparison against current } \\
\text { study results }\end{array}$ \\
\hline Zis, 2014 [23] & Greece & 263 & $\begin{array}{l}14.4 \% \text { of the residents were found to experience } \\
\text { burnout }\end{array}$ & $\begin{array}{l}\text { Slightly higher prevalence rate } \\
\text { of burnout }\end{array}$ \\
\hline $\begin{array}{l}\text { Abdulrahman, } \\
2018 \text { [24] }\end{array}$ & UAE & 302 & $\begin{array}{l}75.5 \% \text { moderate-to-high EE, } 84 \% \text { had high DP, } \\
\text { and } 74 \% \text { had a low sense of PA. }\end{array}$ & Higher EE, DP and PA. \\
\hline $\begin{array}{l}\text { Afzal, } \\
2010[25]\end{array}$ & USA & 115 & $\begin{array}{l}34 \% \text { reported high EE, } 30 \% \text { reported high DP } \\
\text { and } 24 \% \text { reported low PA }\end{array}$ & Lower EE, DP and PA \\
\hline $\begin{array}{l}\text { Agha, } \\
2015[26]\end{array}$ & KSA & 96 & $\begin{array}{l}\text { Overall, } 88.5 \% \text { experienced burnout, with high } \\
\text { EE in } 68.8 \% \text {, high DP in } 63.6 \% \text { and low PA in } \\
38.5 \% \text {. }\end{array}$ & $\begin{array}{l}\text { Higher prevalence rate of } \\
\text { burnout, EE and DP. With } \\
\text { lower PA. }\end{array}$ \\
\hline $\begin{array}{l}\text { AlDubai, } \\
2013[27]\end{array}$ & Malaysia & 205 & $\begin{array}{l}\text { High EE was reported by } 36.6 \% \text { of the } \\
\text { respondents. DP and PA were not reported. }\end{array}$ & Lower EE, \\
\hline $\begin{array}{l}\text { Ben Zid, } \\
2018[28]\end{array}$ & Tunisia & 149 & $17.14 \%$ had a high level of burnout & Higher prevalence of burnout. \\
\hline $\begin{array}{l}\text { Chaukos, } \\
2016[29]\end{array}$ & USA & 68 & $\begin{array}{l}28 \% \text { of resident physicians had a high level of } \\
\text { burnout. }\end{array}$ & Higher prevalence of burnout. \\
\hline $\begin{array}{l}\text { Chen, } \\
2013[30]\end{array}$ & Taiwan & 809 & $\begin{array}{l}13.1 \% \text { reported high EE. } 9.3 \% \text { reported high DP, } \\
\text { and } 0.7 \% \text { reported high level of decreased PA }\end{array}$ & Lower EE, DP and PA. \\
\hline $\begin{array}{l}\text { Cheng, } \\
2020[31]\end{array}$ & $\square$ USA & $\square 105$ & $71 \%$ prevalence of burnout. & $\begin{array}{l}\text { Higher prevalence rate of } \\
\text { burnout. }\end{array}$ \\
\hline $\begin{array}{l}\text { Cristina- } \\
\text { Nituica } \\
2021[32]\end{array}$ & USA & 682 & $51 \%$ prevalence of burnout of burnout. & $\begin{array}{l}\text { Higher prevalence rate of } \\
\text { burnout. }\end{array}$ \\
\hline $\begin{array}{l}\text { Ofei-Dodoo, } \\
2019 \text { [33] }\end{array}$ & USA & 218 & $\begin{array}{l}43 \% \text { prevalence for burnout, } 32 \% \text { reported high } \\
\text { EE, } 31 \% \text { high DP, and } 22 \% \text { high level of } \\
\text { decreased PA. }\end{array}$ & $\begin{array}{l}\text { Higher prevalence rate of } \\
\text { burnout. Lower EE, DP and } \\
\text { PA. }\end{array}$ \\
\hline
\end{tabular}




\begin{tabular}{l|l|l|l|l}
\hline $\begin{array}{l}\text { Ogundipe } \\
2013[34]\end{array}$ & Nigeria & 204 & $\begin{array}{l}\text { 45.6\% had a high level of EE, 57.8\% had high DP } \\
\text { and 61.8\% with high level of decreased PA. }\end{array}$ & Lower EE, DP and PA. \\
\hline $\begin{array}{l}\text { Alhaffar, } \\
2019[35]\end{array}$ & Syria & 3350 & $19.3 \%$ prevalence of burnout syndrome. & Higher prevalence of burnout. \\
\hline $\begin{array}{l}\text { Ferguson, } \\
2020[36]\end{array}$ & Canada & 718 & $\begin{array}{l}\text { 69.4\%. prevalence of burnout, with 61.6\% high } \\
\text { EE, } 47.8 \% \text { high DP and 29.0\% high level of } \\
\text { decreased PA. }\end{array}$ & $\begin{array}{l}\text { Higher prevalence of burnout. } \\
\text { Lower EE, DP and PA. }\end{array}$ \\
\hline
\end{tabular}

\section{Discussion}

This was a cross-sectional study designed to assess the prevalence of burnout syndrome and its related factors in a sample of resident physicians in Sudan. The results of the current study showed $13.9 \%$ prevalence rate of burnout among the participants (Table 2). Similar to a study conducted among resident physicians in Greece, in which $14.4 \%$ of residents met the criteria for burnout [23]. Additionally, a cross sectional survey in Tunisia concluded that $17.14 \%$ of resident physicians had a high level of burnout [28]. Another study in Syria [35] reported 19.3\% prevalence rate of burnout syndrome among resident physicians.

In comparing the reported prevalence rate of burnout to existing literature, most crosssectional studies of burnout syndrome have showed higher prevalence of burnout syndrome among resident physicians in other countries, compared to the results of the current study in Sudan (presented in Table 4). This could be explained by that most of these studies had used the short and abbreviated version of The Maslach Burnout Inventory, which was reported to overestimate the prevalence of burnout syndrome among resident physicians [37]. More importantly, the prevalence rate of burnout reported in the present study results is similar to other studies of burnout among other clinicians and health personnel in Sudan [38, 39], lending support to our findings.

In the analysis of parameters linked to burnout syndrome and its dimensions, there were significant differences noted across specialties with pediatric trainee suffer higher levels (Table 3). In support to this finding many other studies showed that pediatric resident with a higher risk, and suffer higher levels, of burnout syndrome [40-44]. Additionally, burnout rate was positively associated with working hours per duty of resident physicians. This finding was supported by results of a study conducted among resident physicians in Saudi Arabia which established the positive association between the resident duty working hours and burnout syndrome[45]. Moreover, there were no significant differences in burnout rates related to sociodemographic factors residents, age groups, gender, years of residency experience marital status (Table 3). A similar findings 
was reported in previously research of burnout among resident physicians in South Africa [46] and USA[47].

\section{Limitations}

The current study doesn't assess neither the level of stress, awareness of coping strategies nor job satisfaction among resident physicians in Sudan to avoid a long questionnaire. Hence, the selection of explanatory variables wasn't theoretically grounded. However, the study was able to provide preliminary evidence regarding prevalence rate of burnout syndrome among resident physicians in Sudan. Since the study was conducted in Gezira state only, due to lack of sufficient resources for a nationwide survey, the results of study cannot be generalized to resident physicians in other states of Sudan.

\section{Conclusions}

The study revealed high prevalence of burnout syndrome among the sample of resident physicians in Sudan, with the pediatric registrars being especially vulnerable. There was a significant difference in the level of burnout according to respondents' working hours per duty. More studies are required to investigate the level of stress, awareness level of coping strategies, and job satisfaction among resident physicians in Sudan and to examine the association of these factors with burnout syndrome.

\section{Statements and Declarations}

\section{Funding}

None.

\section{Acknowledgments}

We would like to acknowledge the contributions of Dr. Adrian Rabe, PhD and his assistance in the current study.

\section{Conflict of interest statement}

Authors declare no conflict of interest. 


\section{Authors contributions}

Conceptualization: [Yasir Ahmed Mohamed Elhadi, and Abdelmuniem Ahmed]; Data curation, Formal analysis and investigation:[All authors], Writing - original draft preparation: [Yasir Ahmed Mohamed Elhadi, Elhadi B. Salih, Osman S. Abdelhamid, and Mohamed Hayder Hamid Ahmed)]; Writing - review and editing: [All authors]; Supervision: [Noha Ahmed El Dabbah].

\section{References}

1. Freudenberger HJ. Staff Burn-Out. J Soc Issues. 1974;30:159-65. doi:10.1111/j.15404560.1974.tb00706.x.

2. WHO. Burn-out an "occupational phenomenon": International Classification of Diseases. 2019. https://www.who.int/news/item/28-05-2019-burn-out-an-occupationalphenomenon-international-classification-of-diseases. Accessed 18 Apr 2021.

3. Maslach C, Jackson SE. The measurement of experienced burnout. J Organ Behav. 1981;2:99-113.

4. De Hert S. Burnout in healthcare workers: Prevalence, impact and preventative strategies. Local and Regional Anesthesia. 2020;13:171-83. doi:10.2147/LRA.S240564.

5. Portoghese I, Galletta M, Coppola RC, Finco G, Campagna M. Burnout and workload among health care workers: The moderating role of job control. Saf Health Work. 2014;5:152-7.

6. Elbarazi I, Loney T, Yousef S, Elias A. Prevalence of and factors associated with burnout among health care professionals in Arab countries: A systematic review. BMC Health Serv Res. 2017;17. doi:10.1186/s12913-017-2319-8.

7. Wang J, Wang W, Laureys S, Di H. Burnout syndrome in healthcare professionals who care for patients with prolonged disorders of consciousness: A cross-sectional survey. BMC Health Serv Res. 2020;20:841. doi:10.1186/s12913-020-05694-5.

8. Del Carmen MG, Herman J, Rao S, Hidrue MK, Ting D, Lehrhoff SR, et al. Trends and Factors Associated With Physician Burnout at a Multispecialty Academic Faculty Practice Organization. JAMA Netw open. 2019;2:e190554.

doi:10.1001/jamanetworkopen.2019.0554.

9. Zhou AY, Panagioti M, Esmail A, Agius R, Van Tongeren M, Bower P. Factors Associated with Burnout and Stress in Trainee Physicians: A Systematic Review and Meta-analysis. JAMA Netw Open. 2020;3. doi:10.1001/jamanetworkopen.2020.13761.

10. Shanafelt TD, Balch CM, Bechamps GJ, Russell T, Dyrbye L, Satele D, et al. Burnout and career satisfaction among american surgeons. Ann Surg. 2009;250:463-70. 
doi:10.1097/SLA.0b013e3181ac4dfd.

11. Shanafelt TD, Gradishar WJ, Kosty M, Satele D, Chew H, Horn L, et al. Burnout and career satisfaction among US oncologists. J Clin Oncol. 2014;32:678-86.

doi:10.1200/JCO.2013.51.8480.

12. Shanafelt TD, Gorringe G, Menaker R, Storz KA, Reeves D, Buskirk SJ, et al. Impact of organizational leadership on physician burnout and satisfaction. Mayo Clin Proc. 2015;90:432-40. doi:10.1016/j.mayocp.2015.01.012.

13. Fred HL, Scheid MS. Physician burnout: Causes, consequences, and (?) Cures. Texas Heart Institute Journal. 2018;45:198-202. doi:10.14503/THIJ-18-6842.

14. Lacy BE, Chan JL. Physician Burnout: The Hidden Health Care Crisis. Clin Gastroenterol Hepatol. 2018;16:311-7. doi:10.1016/j.cgh.2017.06.043.

15. Sudan Medical Specialization Board | Health Information For All (HIFA.ORG). https://www.hifa.org/support/supporting-organisations/sudan-medical-specializationboard. Accessed 10 Nov 2021.

16. WHO. Global Health Workforce Alliance. https://www.who.int/workforcealliance/countries/sdn/en/. Accessed 10 Nov 2021.

17. Fadul N, Hussein ME, Fadul AA. Re-opening Sudan: the Balance Between Maintaining Daily Living and Avoiding the Next Peak of COVID-19. Current Tropical Medicine Reports. 2021;8:231-7. doi:10.1007/s40475-021-00237-2.

18. Hu NC, Chen JD, Cheng TJ. The associations between long working hours, physical inactivity, and burnout. J Occup Environ Med. 2016;58:514-8. doi:10.1097/JOM.0000000000000715.

19. Maslach C, Jackson S, Leiter M. Malasch Burnout Inventory (3rd edition). Evaluating Stress: A Book of Resources, Volume 1. 1986;:191-218.

20. Mind Garden. https://www.mindgarden.com/. Accessed 11 Nov 2021.

21. Poghosyan L, Aiken LH, Sloane DM. Factor structure of the Maslach burnout inventory: An analysis of data from large scale cross-sectional surveys of nurses from eight countries. Int J Nurs Stud. 2009;46:894-902.

22. Gan Y, Jiang H, Li L, Yang Y, Wang C, Liu J, et al. Prevalence of burnout and associated factors among general practitioners in Hubei, China: A cross-sectional study. BMC Public Health. 2019;19:1607. doi:10.1186/s12889-019-7755-4.

23. Zis P, Anagnostopoulos F, Sykioti P. Burnout in Medical Residents: A Study Based on the Job Demands-Resources Model. Sci World J. 2014;2014. doi:10.1155/2014/673279. 
24. Abdulrahman M, Farooq M, Al Kharmiri A, Al Marzooqi F, Carrick F. Burnout and depression among medical residents in the United Arab Emirates: A Multicenter study. J Fam Med Prim care. 2018;7:435. doi:10.4103/JFMPC.JFMPC_199_17.

25. Afzal KI, Khan FM, Mulla Z, Akins R, Ledger E, Giordano FL. Primary language and cultural background as factors in resident burnout in medical specialties: a study in a bilingual US city. South Med J. 2010;103:607-15. doi:10.1097/SMJ.0B013E3181E20CAD.

26. Agha A, Mordy A, Anwar E, Saleh N, Rashid I, Saeed M. Burnout among middlegrade doctors of tertiary care hospital in Saudi Arabia. Work. 2015;51:839-47. doi:10.3233/WOR-141898.

27. Al-Dubai SAR, Ganasegeran K, Perianayagam W, Rampal KG. Emotional burnout, perceived sources of job stress, professional fulfillment, and engagement among medical residents in Malaysia. Sci World J. 2013;2013.

28. Ben Zid A, Homri W, Ben Romdhane I, Bram N, Labbane R. [Burnout in Tunisian medical residents: About 149 cases]. Encephale. 2018;44:337-42. doi:10.1016/J.ENCEP.2017.06.006.

29. Chaukos D, Chad-Friedman E, Mehta DH, Byerly L, Celik A, McCoy TH, et al. Risk and Resilience Factors Associated with Resident Burnout. Acad Psychiatry. 2017;41:189-94. doi:10.1007/S40596-016-0628-6/FIGURES/1.

30. Chen KY, Yang CM, Lien CH, Chiou HY, Lin MR, Chang HR, et al. Burnout, Job Satisfaction, and Medical Malpractice among Physicians. Int J Med Sci. 2013;10:1471. doi:10.7150/IJMS.6743.

31. Cheng MY, Neves SL, Rainwater J, Wang JZ, Davari P, Maverakis E, et al. Exploration of Mistreatment and Burnout Among Resident Physicians: a Cross-Specialty Observational Study. Med Sci Educ. 2020;30:315-21. doi:10.1007/S40670-019-00905Z/TABLES/2.

32. Nituica C, Bota OA, Blebea J. Specialty differences in resident resilience and burnout - A national survey. Am J Surg. 2021;222:319-28.

doi:10.1016/J.AMJSURG.2020.12.039.

33. Ofei-Dodoo S, Callaway P, Engels K. Prevalence and Etiology of Burnout in a Community-Based Graduate Medical Education System: A Mixed-Methods Study. Fam Med. 2019;51:766-71. doi:10.22454/FAMMED.2019.431489.

34. Ogundipe OA, Olagunju AT, Lasebikan VO, Coker AO. Burnout among doctors in residency training in a tertiary hospital. Asian J Psychiatr. 2014;10:27-32. doi:10.1016/J.AJP.2014.02.010.

35. Alhaffar BA, Abbas G, Alhaffar AA. The prevalence of burnout syndrome among resident physicians in Syria. J Occup Med Toxicol. 2019;14. doi:10.1186/S12995-019- 
0250-0.

36. Ferguson C, Low G, Shiau G. Resident physician burnout: insights from a Canadian multispecialty survey. Postgrad Med J. 2020;96:331-8. doi:10.1136/POSTGRADMEDJ2019-137314.

37. Lim WY, Ong J, Ong S, Hao Y, Abdullah HR, Koh DLK, et al. The Abbreviated Maslach Burnout Inventory Can Overestimate Burnout: A Study of Anesthesiology Residents. J Clin Med 2020, Vol 9, Page 61. 2019;9:61. doi:10.3390/JCM9010061.

38. Ahmed DMM, Abdulhamid DOH, Suleiman DIEE. The Prevalence and Factors associated with Burnout among Sudanese Health Care Professionals at Primary Health Care Centers in Wad Madani Al-Kubra (Sudan), and Sharjah (UAE), 20 October - 20 November 2020. Acad J Res Sci Publ. 2021;3:5-27.

39. Hamid AAM, Abdullah AS. Job distress and burnout among Tanzanian and Sudanese health professionals: a comparative study. South African J Psychol. 2020;50:411-24.

40. Bin Dahmash A, Alajmi MF, Aldayel AY, Alotaibi YT, Altoum SM, Alzayed A, et al. Burnout and Associated Risk Factors in Pediatric Residents. Ochsner J. 2021;21:1527. doi:10.31486/TOJ.20.0037.

41. Baer TE, Feraco AM, Sagalowsky ST, Williams D, Litman HJ, Vinci RJ. Pediatric resident burnout and attitudes toward patients. Pediatrics. 2017;139:20162163. doi:10.1542/PEDS.2016-2163/53410.

42. McKinley TF, Boland KA, Mahan JD. Burnout and interventions in pediatric residency: A literature review. Burn Res. 2017;6:9-17.

43. Jamjoom RS, Park YS. Assessment of pediatric residents burnout in a tertiary academic centre. Saudi Med J. 2018;39:296. doi:10.15537/SMJ.2018.3.22328.

44. Mahan JD. Burnout in pediatric residents and physicians: A call to action. Pediatrics. 2017;139. doi:10.1542/PEDS.2016-4233/53777.

45. Hameed TK, Masuadi E, Al Asmary NA, Al-Anzi FG, Al Dubayee MS. A study of resident duty hours and burnout in a sample of Saudi residents. BMC Med Educ. 2018;18:1-6. doi:10.1186/S12909-018-1300-5/TABLES/3.

46. Zeijlemaker C, Moosa S. The prevalence of burnout among registrars in the School of Clinical Medicine at the University of the Witwatersrand, Johannesburg, South Africa. S Afr Med J. 2019;109:668-72. doi:10.7196/SAMJ.2019.V109I9.13667.

47. Nituica C, Bota OA, Blebea J, Cheng CI, Slotman GJ. Factors influencing resilience and burnout among resident physicians - a National Survey. BMC Med Educ. 2021;21. doi:10.1186/S12909-021-02950-Y. 